great drawbacks. The estuary or river, on which the little Volta was lying placidly, is ten miles in breadth between Leopard's Island and Cape Sierra Leone; extends inland about twenty miles, where it divides into several arms, one of which, the Robelle, is said to have its source twenty miles from Fallaba, and two hundred from Sierra Leone, the usual rapids or falls intercepting fifty or sixty miles from Freetown. [To be continued.]

\section{THE PATHOLOGY OF CANCER.}

BY SAMUEL WILKS, M.D., F.R.S., Physician and Lecturer on Medicine at Guy's Hospital.

As an old member of the Pathological Society, I had hoped to be present at its last meeting, to offer my opinion on the subject of Cancer ; but unfortunately, the examination at the College of Surgeons prevented me. It may now be forgotten that I had always advocated at the Society the views advanced by Mr. De Morgan in favour of what is called the "local" theory, in distinction to the "constitutional", and I did so, because I believed that the study of morbid anatomy had done much to upset the long prevalent teaching concerning the nature of cancer derived alone from clinical medicine and surgery. The opinions I was in the habit of expressing are contained in a paper* which I now forward, and of which the following is a summary.

It was the teaching of the schools that certain morbid growths were apt to spring up in the body ; if these were removed, they would burst forth again and spread ; moreover, since some of the victims' ancestry were subject to the same form of disease, it was clear that a deep. seated inherited vice existed in the constitution for its production. Works on medicine and surgery supported this view, and at the present time the nomenclature of the College of Physicians would lead us to believe that the different organs and tissues of the body are not only liable to inflammation and its consequences, but subject to the formation of tubercle, cancer, and other growths.

Now, I would say, in the first place, that this doctrine is not true. All parts of the body are not liable to undergo spontaneously these morbid changes, but the latter are strictly limited; in all probability each tissue has its own pathological deviations in a determined special direction; and, without mentioning other matters, I would say that cancer affects more especially the cellular tissue in connection with the skin and mucous membrane, and that the viscera, with many other tissues, are not primarily attacked. Thus, cancer of the lung is a disease of which I have no knowledge, and yet this organ affords an excellent soil for it when transplanted therein. Some structures of the body are seldom found diseased in any way, whilst others are not subject to cancer, nor others to tubercle. Those who will not advance with me as far as this, will admit that cancer of the lung and other viscera is generally secondary, and that all parts of the body are not prone alike to the disease. If, with me, it be conceded that cancer never springs up primarily in the lung, it must follow that the seeds of it have been conveyed from another source.

It is a remarkable fact that surgeons, ever since their art has recognised the possibility of removing cancerous tumours by operation, have assumed and acted upon the doctrine before mentioned; that is, the local origin of the disease. For, although the operator feared a repetition of the growth or its appearance within the body, yet, at the time of its removal, he regarded it as local. He never believed he had before him a patient possessing such a cancerous constitution that he was full of malignant disease, and that his own skill was useless on that account. His experience had, on the other hand, told him that the cancer he was about to remove was quite local, as it generally was when seen on the outside of the body. If this had not been so, but the cancer due to a deep constitutional cause springing up indiscriminately here, there and everywhere, there had been no occasion for any discussion as to the local or constitutional nature of the disease.

Now, if it be true that cancer, having so common an element as cell structure, is limited in its growth, much more is it true of other malignant tumours which have a special nature. These clearly arise under a local influence; thus I have seen a few cases of osteoid disease, and have read of others, that is, cases where bony tumours have been found in the abdomen, lungs, and other parts. Now, in all these cases, the prime disease originated in a part of the bony skeleton. It was this which determined their growth, and, therefore, there is no disease of the system which can be strictly styled osteoid disease. In the same manner, melanosis is seen to arise in a mole, on the choroid of the eye, and then rapidly propagate over the skin where pigment prevails. Epithelialgrowths

* On the Value of the Study of Morbid Anatomy (Guy's Hospital Reports, 1865). have been met with in the lungs, liver, and suprarenal capsules; but no one has yet described primary epithelioma in these organs ; it has been secondary to disease in the œesophagus. Other forms of cancer also vary with the structure in which they arise, as scirrhus in dense organs like the breast, and encephaloid in the softer parts. Here, then, we see various forms of disease springing up in the body ; there may se some deep-seated cause transmitted by the ancestry, which sets the process in operation, or there may not ; but, that their character is determined in part by local circumstances is clear, and in this way are produced the above-named osteoid, melanoid, epithelial, scirrhous, and encephaloid diseases. When, also, we find these growths presenting the same identical characters throughout the body, we recognise the local work.

It would follow that, if an osteoid tumour of an internal organ be not primary, but always follows the production of a local one on a bone, it must have been derived from the latter, and, therefore, there must have been a time in the history of the case when the primary growth was not sufficiently well developed to infect the system. Whether this time can be practically known to the surgeon, is another question. In epithelioma, where the seeds are sown as well as grow with more difficulty, a period in which eradication may be effected does exist. If a case be taken hypothetically, that a growth of cells has sprung up in a part of the body from a purely local cause, and that elementary particles of those cells are ever ready to pass into the lymphatic and venous circulation to be propagated in distant parts, the chances are immensely against any surgeon removing that growth in its entirety, at such a time when it has been first discovered, without leaving a cell behind. The whole theory of cancer, its terrible nature and malignancy, means that it propagates through the system. When the surgeon operates, he often knows that the adjacent parts are involved, or, if he do not, they may often be found (if the patient die after the operation) to be so by naked eye or microscopic inspection. In fact, it were about as impossible to remove a mass of cells, numbering millions in multitude, without leaving some behind, as it would be to endeavour to eradicate a mass of weeds from a garden so that not a single one should spring up again. With this almost supreme impossibility of a surgeon being able to remove a soft mass of cells without leaving some behind, I do not know why he should have recourse to a theory that the seeds of the disease are in the constitution; he does not say this when he fails to arrest the effects of a venomous bite by cauterisation, or the results of syphilis by excision of the chancre.

According to a prevailing view, there were different forms of cancer, possessing different degrees of malignancy, which, of course, imply different degrees of intensity of the cancerous diethesis; but it can be clearly shown that these varieties of malignancy are due to accidental causes alone. For let there be two persons, man and woman, exactly alike in every respect; let them be, in fact, twins, with the same predispositions, and let the one have a blow on the testis and the other a blow on the mamma ; we know, from experience, that in the one case the cancer (if it occurred) would be scirrhous, and, in the other case, encephaloid, the differences being due to local causes, and yet the man might only survive the appearance of the disease six months, whereas the woman might live six years.

Then, again, the various degrees of malignancy, as described by some authors, are clearly due to the difficulties and facilities of removal ; and, in consequence, malignant disease of the tongue is a worse form than malignant disease of the lip or scrotum.

Cancer may exist for years without any evidence of constitutional disturbance, as seen occasionally in the breast. It may also dry up, and be, in fact, cured, which is also sometimes seen in the breast, and occasionally in the internal organs.

A cancerous cachexia has been held by some as indicative of a prior constitutional cause operating in the system, but more careful observations show that the so-called malignant aspect attaches itself to internal cancers of vital organs and not to external tumours. With the latter, patients look fresh and fat, and with diseases other than cancerous affecting mortally the liver and stomach, the same cachectic aspect is apparent.

Hereditary tendency, as described by many authors, appears to be almost in proportion to the readiness with which disease is recognised. Thus it is said to be more easily traceable in insanity than any other disorder, but this may be owing to aberrations of intellect being more perceptible than aberrations of the functions of other organs, as the liver ; and, so it is, that tubercle, cancer, etc., are picked out as evincing hereditary tendencies to develope themsclves. At present I think we can say no more than that the question of diathesis is one of the utmost importance ; that people are constituted differently, and have proclivities to particular morbid changes, but my own experience is that there is no more hereditary proclivity to cancer than any other morbid condition. 
The difficulties of understanding the propagation of new growths through the blood are not greater than in the cases of pyæmia, syphilis, or inoculated variola, nor in the cases of the diffusion of lead, mercury, or silver through the system.

Malignant disease means a form of malady which infects the whole system from a local source. The character of the disease clearly depends in great measure on local influences. Some new formations cannot propogate themselves, and others can; this depends on their structure. Why is the body liable to a number of local affections which vary in this way? Here lies a difficulty; but, because it cannot be answered, it does not follow that it is due to some inherent vice in the system. Ten different persons may have ten different morbid actions arise on a defined spot on the body. One man may have a sebaceous tumour on his head, another a patch of lepra on his chest, another an ulcer on his leg, another a warty growth on his finger, another an enchondroma on his toe, another an epithelioma on his scrotum, another have a growth made up of nucleated cells on his neck, another have a tumour made up of bone on the thigh, another have a fatty tumour on his shoulder, and the tenth a black tumour growing up in a mole. Now, if we take these different morbid conditions, we call some innocent and others malignant, because the former remain localised and the others spread. Is this difference in their structure associated with their spreading, due to some constitutional difference in the subject, or are local causes only in operation? I should say, without disputing the question of tendencies in persons to different morbid actions, that the old doctrine, and that taught generally up to the present time, that constitutional causes are alone in operation, is refuted by the arguments before given. It is possible that, looking upon the constitutional and local causes as distinct, we may be only regarding the one side of the shield. If there be two sides, I should say that clinical surgery had, until late years, looked at the one side only, and that morbid anatomy had given us the other side of the picture.

Some of the more evident arguments, taken from the fact of cancer returning on the same-spot from whence it was supposed to be removed, or in the adjacent glands, and similar facts, need not be repeated.

\section{TEMPORARY AFFECTION OF SPEECH (APHASIA) : "APHASIC" WRITING.}

By J. HUGHLINGS JACKSON, M.D.,

Physician to the London Hospital and to the Hospital for Epilepsy and Paralysis.

THIS case is of interest, as showing temporary loss, or rather great defect, of speech, with inability to write and to read. There was, to use the accepted nomenclature, Aphasia. I report it because I can give a specimen of the writing, or, so to put it, of the inability to write -that is, to speak in writing. My friend Mr. Steggall was so kind as to draw my attention to the case, and to procure for me the specimen of writing mentioned.

The patient, an intelligent Scotchman, forty-two years of age, had had five attacks, in the last three of which there was loss of speech. It is necessary to give an account of all his attacks, for the sake of the pathology of the case. My belief is, that the several symptoms were the results of thrombosis of very small cerebral arteries; but, most unfortunately, I put off going into the clinical pathology of the case (state of arteries, heart, urine, etc.) until another occasion : I never saw the patient again. I have elsewhere described what may be called Epileptic Aphasia ; but the temporary affections of speech in this case were not, I think, of that kind.

First Attack, October 1870.-After walking more than a mile to his shop, he opened his shop, and then went outside to brush dust off the window-frame. The left arm suddenly lost power, and the leg became weak. There was, however, a trifling power of movement in the arm, and, by the time that Mr. Steggall reached him, it was recovering. The same evening, he served in his shop, and also next day. The arm was still weak, but he could use it for measuring and unrolling ribbons, etc.; however, he did not absolutely recover. - Eight days later, he had his second attack.

Second Attack.-He was out, and was again seized in the left arm and leg. He went home "drawing the left leg after him". In this attack, the leg suffered more than it did in the first, but still was not so much affected as the arm was in this second attack. In a week, he could do some work, but was under medical care a month, at the end of which time he was nearly well, but had had ever since numbness of the left finger-ends.

In both attacks, he seems to have had some defect of sensation in the paralysed parts. He thinks the face was not drawn in either attack, but it felt stiff. There was no trace of loss of consciousness in either, and no vestige of cramp or spasm.
Third Attack.-On Friday, January 20th, 1871, at 8 P.M., when in the shop, he suddenly felt that his speech had gone. He tried to speak aloud, and could only mumble. A customer came in for a pair of stockings; he could not speak to her, and went into the parlour, beckoning to his wife to go into the shop to take his place. He was better in two hours, and next morning was all right.

Fourth Attack.-On Tuesday morning, January 24th, 1871, he found his speech gone when he got up. He went down stairs, lit the fire, and boiled the kettle. He opened the shop, but could not speak to his customers. He had not, however, lost the power of uttering something, as he made mistakes-" said what was quite different". He can only call to mind one of his mistakes; viz., "penly" for "penny". So he gave up serving, and tried to tell his wife that he would go for a walk. He could not say it. At her suggestion, he tried to write it, and could not. The woodcut shows the result of his effort. As he

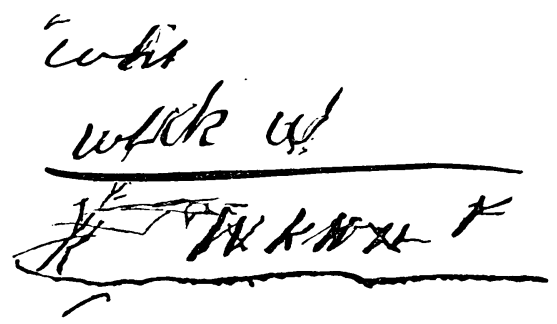

says, since he could not "write" it, he tried to "print" it, as in the last line. I asked him why he could not write; he said he did not know, and added that he could not spell. There was nothing wrong with his arm. He tried to read the newspaper, but could not. I again asked why. He said he did not know ; "seems as if sense was gone;" "could not make words out." His sight was not affected; he began at the top of an article. "I dare say I read a word, but I could not make any meaning out of it". He lay down and slept from midday to 8 or 9 in the evening. When he awoke, he could speak plainly, but not for long; "soon came back to the old mumble". He went to bed at Io, and next morning could speak quite well again.

Fifth Attack, Thursday next.-On awaking, he could not speak, and did not speak for an hour. Unfortunately, he did not try to write, except on the occasions referred to.

In none of these attacks did he find anything wrong with his face or tongue.

He seemed to be in good health; and the only thing complained of was pain in the left temporal region (a most important symptom), and numbness of the left side of the face, and numbness of the left fingers. As I have said, I have no details of the clinical pathology.

\section{O N A P H ASIA.}

By T. CLAYE SHAW, M.D.,

Medical Superintendent of the Metropolitan Asylum, Leavesden; Lecturer on Psychological Medicine at St. Bartholomew's Hospital.

IN the present state of opinion regarding the connection of aphasia with the lesion of a defined portion of the brain, all cases bearing directly on the subject should be put on record. Subjoined are the history and post mortem examination of a man aged 74 , a tailor by trade, who suffered from well marked amnesic aphasia. According to his wife's account, he was always temperate, and had never smoked. The first paralytic seizure occurred in March 1867 , but sight and memory had somewhat failed eighteen months before. At this period (1867), the right extremities were paralysed; and the aphasic condition was present, for he gave to understand by signs that he wanted a slate and pencil to express himself with, not being able to say what he wished; and yet he could not write intelligibly when the materials were given to him. He called his wife "Joe" and "Jack", complained of the right side of his face and head feeling " too large", and answered questions incoherently. In September 1867 , he became epileptic, and was under treatment at the Queen Square Hospital for some months. Afterwards he became violent, and hid knives and ropes with the avowed intention of using them against others. In June 1872, he was admitted into the Leavesden Asylum, in the following state. He was right-handed. The body was fairly nourished. There was right hemiplegia, with contraction of the extremities, and drawing of the face from palsy of the left facial muscles. He had epileptic fits about once a month, the right extremities being always much involved in the seizures. He had great difficulty in getting out the word he wanted to say; e.g., he could not 